Rev. Elet. em Gestão, Educação e Tecnologia Ambiental (e-ISSN: 2236-1170)

\title{
GESTÃO AMBIENTAL E SUSTENTABILIDADE: UM ESTUDO DE CASOS MÚLTIPLOS NO SETOR HOTELEIRO DE JOÃO PESSOA/PB.
}

\section{ENVIRONMENTAL MANAGEMENT AND SUSTAINABILITY: A STUDY OF CASES MULTIPLE ON SECTOR HOTEL BY JOÃO PESSOA/PB.}

\author{
Vagner de Souza Felix', Joel Silva dos Santos ${ }^{2}$
}

\author{
${ }^{1}$ Bacharel em Ecologia pela UFPB/DEMA. João Pessoa/PB - Brasil. vagnerdfelix@gmail.com \\ ${ }^{2}$ Professor Dr. da UFPB/DEMA; João Pessoa/PB - Brasil. joelsilvadossantossantos@yahoo.com.br
}

http://dx.doi.org/10.5902/223611707855

\begin{abstract}
RESUMO
Este artigo procura identificar as diversas práticas de gestão ambiental adotadas por alguns hotéis da rede hoteleira de João Pessoa, PB. O trabalho discute a importância da adoção do Sistema de Gestão Ambiental para a materialização da sustentabilidade ambiental nesse segmento. A pesquisa também tem o objetivo de verificar os principais impactos ambientais gerados pelos hotéis investigados, bem como, traçar o perfil socioambiental dos mesmos, no que diz respeito, ao uso dos recursos naturais e a sustentabilidade ambiental. Para a realização da pesquisa, inicialmente foi feito um levantamento bibliográfico a respeito da temática em questão, seguido de uma investigação documental nos órgãos competentes para verificar o cumprimento da legislação ambiental por parte das empresas investigadas. Foi realizado também a aplicação de questionário temático e visita técnica com o objetivo de atestar as informações da pesquisa. Dessa forma, verificou-se que o setor hoteleiro do município de João Pessoa, ainda carece de práticas de gestão ambiental que possibilitem o uso sustentável dos diversos recursos naturais.
\end{abstract}

Palavra-chaves: Sistema de gestão ambiental; sustentabilidade; uso dos recursos naturais.

\begin{abstract}
This article seeks to identify the various environmental management practices adopted by some of the hotel chain hotels in Joao Pessoa, PB. The paper discusses the importance of the adoption of Environmental Management System for the materialization of environmental sustainability in this segment. The research also aims check the main environmental impacts generated by the hotels investigated, as well as, social and environmental profiling of the same, with respect to the use of natural resources and environmental sustainability. For the research, was originally done a bibliographic about the topic in question, followed by a documentary research bodies in to verify compliance with environmental legislation by the companies investigated. It was also carried out a questionnaire theme and technical visit in order to certify the survey information. Thus, it was found that the hotel sector of the city of João Pessoa, still lacks environmental management practices that enable the sustainable use of various natural resources.
\end{abstract}

Key words: Environmental Management; Sustainability; use of natural resources; 
Rev. Elet. em Gestão, Educação e Tecnologia Ambiental (e-ISSN: 2236-1170)

O crescimento da população humana, juntamente com o desenvolvimento do sistema capitalista, que rege toda forma de produção industrial e tecnológica, adotado por quase todas as nações do Planeta Terra, vem ocasionando um consumo predatório dos recursos naturais, gerando assim, uma série de impactos ambientais com conseqüências diversas para a sociedade em geral. Nesse processo, as empresas atuam na transformação da matéria - prima (extração dos recursos naturais) e na sua transformação (mercadoria), criando assim, uma série de insumos e impactos nos mais diversos sistemas ambientais.

Segundo Braga et. al. (2005), recurso natural é qualquer insumo que os organismos, as populações e os ecossistemas necessitam para a sua manutenção. No planeta Terra dois tipos de recursos naturais são apresentados: os renováveis e os não renováveis. Os não-renováveis são aqueles que uma vez utilizados não se renovam, causando assim, escassez e limitação. Já os renováveis, são aqueles que podem se renovar naturalmente no decorrer do ciclo da vida do planeta. No entanto, as empresas pautadas em uma matriz energética, poluidora e limitada, optaram por esse modelo em função de interesses econômicos predominantes gerando dessa forma, uma série de problemas ambientais decorrentes da exploração desses recursos.

Em decorrência dos diversos problemas ambientais, as empresas necessitam cada vez mais inserir no contexto da sua cadeia de produção, o conceito de sustentabilidade, objetivando sensibilizar as pessoas e os empresários da necessidade de minimizarem os impactos socioambientais ocasionados por essas grandes corporações e da oportunidade de investir em alternativas de produção mais limpa e eficiente.

Assim, o setor hoteleiro deve ter sua parcela de responsabilidade em fazer da sustentabilidade uma parte integrante de suas metas, já que as mesmas dependem da qualidade do meio ambiente para o seu crescimento (FERREIRA, 1999). Frente a esse desafio, o setor hoteleiro passou a adotar as diversas práticas de gestão ambiental como ferramenta para o turismo sustentável, tentando fugir da realidade da inospitabilidade, que é quando o entorno natural do empreendimento passa a ser degradado pelo turismo de massa (PHILLIPI, 2010). Dessa forma, o setor hoteleiro dever adotar tecnologias alternativas buscando mitigar os impactos ambientais de suas atividades, como, também, se lançarem em busca da sustentabilidade econômica, social e ecológica.

É diante deste contexto que este trabalho se apresenta, com o intuito de realizar uma avaliação de como está sendo introduzido o conceito de sustentabilidade no âmbito organizacional e sua repercussão nas atividades desenvolvidas pelo setor hoteleiro do município de João Pessoa/PB. A pesquisa tem como objetivo principal verificar as práticas de gestão ambiental e sua importância para a promoção da sustentabilidade no setor hoteleiro da cidade de João Pessoa/PB.

\section{OBJETIVOS}

\subsection{Geral}

- Verificar as práticas de gestão ambiental e sua importância para a promoção da sustentabilidade no setor hoteleiro da cidade de João Pessoa/PB. 
Rev. Elet. em Gestão, Educação e Tecnologia Ambiental (e-ISSN: 2236-1170)

\subsection{Específicos}

- Compreender a importância da Gestão Ambiental para o setor hoteleiro e o uso sustentável dos recursos naturais.

- Analisar os fatores externos e internos que levaram à implementação de práticas de gestão ambiental na rede hoteleira;

- Caracterizar o perfil socioambiental dos hotéis quanto à sustentabilidade ambiental;

- Identificar os principais impactos ambientais ocasionados pela rede hoteleira na cidade de João Pessoa, PB;

\section{REVISÃO DA LITERATURA}

\subsection{GESTÃO AMBIENTAL E RESPONSABILIDADE SOCIAL E EMPRESARIAL}

De acordo com May et al. (2003), gestão ambiental é uma estrutura organizacional que consiste em um conjunto de medidas e procedimentos bem definidos que, se adequadamente aplicados, permitem reduzir e controlar os impactos introduzidos por um empreendimento sobre o meio ambiente, seja no momento da produção ou do serviço.

A gestão ambiental foi desenvolvida para alcançar uma melhor sustentabilidade ambiental do empreendimento, ou ainda, a partir dela, chegar a um modelo de desenvolvimento sustentável eficiente para toda a sociedade. Segundo Dias (2009), das instituições existentes nas sociedades humanas, as empresas constituem, hoje, um dos principais agentes responsáveis pela obtenção da sustentabilidade ambiental.

Como afirma Oliveira Filho (2004), a gestão ambiental não questiona a ideologia do crescimento econômico, que é a principal força motriz das atuais políticas econômicas e, tragicamente, da destruição do ambiente global. No entanto, reconhece que o crescimento econômico ilimitado no planeta, com recursos finitos, pode levar a um desastre. Desta forma, faz uma restrição ao conceito de crescimento, introduzindo a sustentabilidade ecológica como critério fundamental de todas as atividades de negócio. O objetivo final na verdade é alcançar a rentabilidade econômica e a conservação dos recursos naturais, ou seja, o desenvolvimento sustentável. Como pode-se perceber, o conceito do desenvolvimento sustentável é muito amplo, envolvendo, segundo vários autores, três grandes fundamentos: a sustentabilidade social, sustentabilidade econômica e sustentabilidade ambiental. Esses fundamentos devem estar interligados, não devendo ocorrer privilégios em um nível sobre os demais.

Segundo Mello (2002) apud Oliveira Filho (2004), a sustentabilidade é o modo de sustentação, ou seja, da qualidade da manutenção de algo. Este algo pode ser considerado o próprio homem, com sua forma de vida enquanto espécie biológica, individualidade psíquica e ser social. Embora, o mesmo possua sua independência cultural, ainda não possui independência do meio que o circunda, a natureza, que se apresenta como fonte geradora de recursos e serviços ambientais. Dessa forma, faz-se necessário a realização de ações que ajudem a gerenciar sua forma de produção e, principalmente, gerenciar os recursos que a natureza disponibiliza.

A sustentabilidade ambiental aparece como uma necessidade de restabelecer o lugar da natureza na teoria econômica e nas práticas do desenvolvimento, internalizando condições ecológicas da produção que assegurem a sobrevivência e um futuro para a humanidade (LEFF, 2011). 
Rev. Elet. em Gestão, Educação e Tecnologia Ambiental (e-ISSN: 2236-1170)

Dessa forma, o Sistema de Gestão Ambiental (SGA) foi desenvolvido com o intuito de se alcançar essa sustentabilidade, em particular, a sustentabilidade do ambiente que circunda o empreendimento e o qual fornece recursos e serviços ambientais para a realização das suas atividades. Sendo assim, só a partir dessa perspectiva e que será possível alcançar mudanças nas demais escalas da sociedade.

Atualmente o segmento hoteleiro passa a despertar um maior interesse a respeito da problemática ambiental, buscando adotar uma atitude diferenciada em relação ao usufruto dos recursos naturais indispensáveis a manutenção das suas atividades. Como afirma Santos et al. (2005), essa tem sido uma maneira encontrada pelos hoteleiros de reduzir seus custos, criar uma boa imagem perante o cliente e estabelecer um diferencial competitivo diante da concorrência acirrada. A aplicação de práticas ambientais e sociais adequadas é uma decisão empresarial sensata, já que estas não somente reduzem custos e melhoram a imagem do hotel, mas também garantem atrativos permanentes do destino para os turistas (MORAES, 2008). Dessa forma, o setor hoteleiro deve adotar tecnologias alternativas buscando mitigar os impactos ambientais de suas atividades, como, também, se lançarem em busca da sustentabilidade econômica, social e ecológica.

Philippi (2010) ressalta que a abrangência do conceito de tecnologias alternativas é muito ampla. Envolvendo aspectos arquitetônicos, economia de energia elétrica, redução do consumo da água, como também realizar o seu tratamento e reutilização da água usa, gerenciamento dos resíduos sólidos. Essas tecnologias alternativas procuram atender as necessidades de consumo com um custo adequado, causando menor impacto ambiental, isso se comparada às tecnologias convencionais. A tecnologia "alternativa", por sua vez, é uma nova maneira de entender a escala e o esquema de funcionamento das atividades técnicas. Nesta perspectiva, o desenvolvimento tecnológico e social devem caminhar juntos, gerando tecnologias que não agridam a biodiversidade e os ecossistemas (ADAM, 2001). Como pode-se perceber, as tecnologias e práticas ambientais adotadas por um empreendimento hoteleiro são bastante amplas no que diz respeito a sua aplicabilidade.

\section{METODOLOGIA}

Durante a realização da pesquisa foram procurados 15 hotéis todos localizados no município de João Pessoa, PB para a aplicação dos questionários e posterior análise. No entanto, dos 15 hotéis apenas dois se propuseram a fazer parte desta investigação.

\subsection{CARACTERIZAÇÃO DOS EMPREENDIMENTOS HOTELEIROS}

\subsubsection{HOTEL A}

O Hotel A, localiza-se em João Pessoa, capital da Paraíba e foi inaugurado em dezembro de 2008, à beira-mar da praia de Manaíra. O empreendimento dispõe de 140 unidades habitacionais e 299 leitos e conta com 80 colaboradores. O hotel é frequentado por turistas de negócios individuais, seguido pelo turismo de eventos e posteriormente, o de lazer. O hotel recebeu o título de Hotel Sustentável do Ano do Guia Quatro Rodas 2012 por fazer uso de tecnologias limpas e ações sustentáveis como: a economia dos recursos naturais, matéria-prima e energia, melhoria 
Rev. Elet. em Gestão, Educação e Tecnologia Ambiental (e-ISSN: 2236-1170)

nas condições de trabalho, incremento na qualidade dos produtos e serviços e diminuição dos custos e conserva.

Dentre as atividades sustentáveis desenvolvidas pelo hotel, pode-se destacar: a coleta seletiva dos resíduos; treinamentos para os colaboradores ficarem envolvidos com a causa ambiental; trabalho educativo com os hóspedes; fardamento em tecido eco-eficiente; utilização de produtos de limpeza biodegradável, reutilização de água para irrigação de jardins, faz uso de aparelhos com baixo consumo de água e energia elétrica e está em fase de implantação da ISO 14001.

\subsubsection{HOTEL B}

O Hotel B fica localizado na Praia de Tambaú em João Pessoa, PB, de frente para o mar. De acordo com os dados disponíveis no site do empreendimento, o estabelecimento possui as seguintes características: confortável, prático e com um atendimento de excelência. O Hotel dispõe de 45 apartamentos, restaurante, piscina com deck, bar, garagem coberta, serviços de lavanderia. O cliente que se hospeda no hotel encontra as seguintes atividades a sua disposição: internet wi-fi, piscina, bicicletas e esteira. O cliente do hotel é do tipo profissional, ou seja, visitante a negócios, com permanência máxima de quatro dias.

Quanto às práticas sustentáveis, o hotel realiza algumas voltadas para a minimização do consumo de energia elétrica, tais como: faz uso de lâmpadas com baixo nível de consumo e utiliza sensores que desligue automaticamente, após a saída do hóspede, os elétricos domésticos presentes nas unidades habitacionais.

\subsection{PROCEDIMENTOS METODOLÓGICOS}

Pesquisa bibliográfica a respeito do tema em questão e investigação documental nos órgãos competentes (SUDEMA) para verificar o cumprimento da legislação ambiental por parte da empresa investigada.

Visita técnica para identificar in locu os principais impactos ambientais gerados pelo hotel no que diz respeito ao uso dos recursos naturais. Também tem o objetivo de verificar as práticas de gestão ambiental adotadas pelo hotel através da aplicação de questionário temático entre os diversos segmentos do empreendimento: gerência, funcionários e hóspedes, este último caso seja disponível. Vale destacar, que no que diz respeito a aplicação dos questionários foram atribuídos pesos para cada questão respondida.

O questionário adaptado de MORAES (2008), Santos et al. (2005) e Ferreira (1999) aborda quatro grandes temáticas; Responsabilidade Socioambiental (legislação e política ambiental); Arquitetura e os Principais Impactos Socioambientais; Práticas de Gestão Ambiental e Uso dos Recursos Naturais e Perfil dos Clientes. O questionário referente à responsabilidade socioambiental foi o respondido pelo Gerente geral do hotel; O questionário referente ao perfil do cliente pelo o Funcionário da recepção. O questionário referente Arquitetura e principais impactos socioambientais pelo funcionário responsável pelo setor de sustentabilidade; O questionário referente às Práticas de Gestão Ambiental pelos os funcionários de serviços gerais, funcionário responsável pelo setor de sustentabilidade, dentre outros, inclusive os hóspedes.

O questionário (anexo) consta de questões aberta e fechadas. As questões abertas foram traçadas no intuito de caracterizar o perfil do cliente do hotel como, também, caracterizar o perfil 
Rev. Elet. em Gestão, Educação e Tecnologia Ambiental (e-ISSN: 2236-1170)

socioambiental do empreendimento, já as fechadas, por sua vez, destinadas a quantificar e qualificar as práticas de gestão ambiental adotadas pelo empreendimento.

A atribuição de peso adotada para cada questão foi dada por grau de relevância quanto à atitude proativa adotada pelo empreendimento em relação ao meio ambiente. Nesse sentido, a atribuição de peso as questões ocorre da seguinte forma: a melhor nota adquirida pela resposta da questão terá o valo numérico de 1 (atitude proativa); já a pior nota dependerá do número de opções que a questão oferecer, podendo ser duas ou mais opções, sendo sempre o valor numérico de 1 para a melhor opção em relação à adoção de uma atitude proativa do empreendimento; $A$ pontuação total, alcançada pelo somatório do resultado das questões respondida pelo hotel, classificará o empreendimento em uma melhor colocação quando comparados aos demais.

Ao final do questionário foi desenvolvida uma avaliação quantitativa e qualitativa do mesmo, tomando como referência a fundamentação teórica utilizada na pesquisa para caracterizar o perfil socioambiental do empreendimento. Para facilitar a análise dos dados pesquisados e melhorar a visualização e interpretação dos itens levantados na pesquisa (questões fechadas) optou-se em criar 06 tabelas de acordo com as temáticas abordadas no questionário.

\section{RESULTADOS E DISCUSSÕES}

\section{1 RESPONSABILIDADE SOCIOAMBIENTAL}

No que se refere ao conceito de responsabilidade socioambiental, observa-se as respostas dadas pelos gerentes de cada empreendimento: $O$ gerente geral do hotel A respondeu: "Entendemos por responsabilidade socioambiental o compromisso que a empresa assume perante as ações sociais e sustentáveis que podem ser desenvolvidas através de atividades de caráter ligado ao tema, a fim de melhorar significativamente o ambiente interno e externo do estabelecimento, atingido positivamente seus clientes, colaboradores, fornecedores, acionistas $e$ sociedade local" (outubro, 2011).

O gerente geral do hotel B respondeu: "Tipo de postura ética por parte das empresas de forma permanente no mercado de consumo e na sociedade: desde a conscientização ao compromisso com os impactos causados aos indivíduos e ao meio ambiente" (outubro, 2011).

A partir do relatado, percebe-se que os hotéis A e B entendem que a responsabilidade socioambiental empresarial é o conjunto de ações desenvolvidas para minimizar os impactos adversos causados pelo desenvolvimento das atividades do empreendimento, seja ele ambiental ou social.

Dessa forma, cabe salientar que o Sistema de Gestão Ambiental é o instrumento desenvolvido para melhor gerenciar os recursos naturais e mitigar os possíveis impactos gerados ao meio ambiente, sendo esse, um instrumento que quando adotado por empresas, tem a função de atuar em prol da sustentabilidade ambiental e, com isso, melhorar a responsabilidade socioambiental da empresa.

Nesse sentido verificou-se também o conceito de gestão ambiental adotado pelo empreendimento. Sendo assim, cada gerente geral adotou um conceito. O gerente do hotel A respondeu: "Entendemos a gestão ambiental como uma nova visão sistêmica de ordenar as atividades humanas para gerar menos impacto negativo sobre o meio ambiente. Esta forma de organização vai desde a escolha das melhores técnicas ou indicadores de eficácia de práticas 
socioambientais, substituição de tecnologia pelas menos poluentes e cumprimento da legislação e a alocação correta de recursos humanos e financeiros" (outubro, 2011).

O Gerente do hotel B respondeu: "É o uso de práticas que garantam a conservação e preservação da biodiversidade e seus materiais, reduzindo o impacto ambiental das atividades humanas sobre os recursos naturais" (outubro, 2011).

Segundo May et. al. (2003) a gestão ambiental é uma estrutura organizacional que consiste em um conjunto de medidas e procedimentos bem definidos que, se adequadamente aplicados, permitem reduzir e controlar os impactos introduzidos por um empreendimento sobre o meio ambiente, seja no momento da produção ou de serviço.

Dessa forma, ao discutir os conceitos de responsabilidade socioambiental e gestão ambiental adotados pelos empreendimentos e vistos na literatura especializada percebe-se que ambos os hotéis possuem conhecimento do tema em questão. No entanto, isso não significa dizer que na prática ambos adotem uma atitude proativa quanto ao uso dos recursos naturais

Avaliando o questionário temático verifica-se no quesito responsabilidade socioambiental (Tabela 1) que o hotel A atingiu uma somatória de 13 pontos, o que classifica o empreendimento como o mais responsável. O hotel $B$ alcançou um somatório de 20 pontos no quesito responsabilidade socioambiental, ficando assim a desejar neste requisito.

Tabela 1: Responsabilidade Socioambiental

\begin{tabular}{|c|c|c|}
\hline Perguntas & Hotel A & Hotel B \\
\hline A empresa possui uma Política Ambiental Interna? & Sim & $\mathrm{Sim}$ \\
\hline O hotel já elaborou algum estudo de impacto ambiental? & Não & Sim \\
\hline A empresa cumpre a Legislação ambiental? & Sim & Sim \\
\hline O empreendimento possui um sistema de gestão ambiental? & $\begin{array}{l}\text { Em fase de } \\
\text { implantação }\end{array}$ & Não \\
\hline $\begin{array}{l}\text { Quais as ações adotadas pela empresa no que diz respeito à } \\
\text { sustentabilidade? }\end{array}$ & $\begin{array}{l}\text { PGA e educação } \\
\text { ambiental com a } \\
\text { comunidade }\end{array}$ & $\begin{array}{l}\text { PGA e educação } \\
\text { ambiental com a } \\
\text { comunidade }\end{array}$ \\
\hline $\begin{array}{l}\text { Caso a empresa não faça uso de ações voltadas para } \\
\text { sustentabilidade, o empreendimento tem o objetivo de adotar } \\
\text { um Sistema de Gestão Ambiental? }\end{array}$ & Faz uso & Sim \\
\hline $\begin{array}{l}\text { A empresa tem conhecimento da certificação ambiental } \\
\text { segundo as normas da série ISO 14000? }\end{array}$ & $\begin{array}{c}\text { Em } \\
\text { implementação }\end{array}$ & Sim \\
\hline A empresa visa à certificação ambiental? & Em adamento & Sim \\
\hline $\begin{array}{l}\text { O hotel realiza medições e monitoramentos periódicos do seu } \\
\text { desempenho ambiental para implementar as ações corretivas e } \\
\text { preventivas que se fazem necessárias para melhoria contínua } \\
\text { de seus resultados? }\end{array}$ & Em andamento & Não \\
\hline $\begin{array}{l}\text { Quais fatores induziram a empresa a aderir práticas de gestão } \\
\text { ambiental? }\end{array}$ & $\begin{array}{l}\text { Cumprir a } \\
\text { legislação } \\
\text { ambiental e } \\
\text { sensibilização }\end{array}$ & $\begin{array}{l}\text { Cumprir a } \\
\text { legislação } \\
\text { ambiental }\end{array}$ \\
\hline $\begin{array}{l}\text { Quais os principais obstáculos que a empresa enfrenta para } \\
\text { introduzir práticas de gestão ambiental? }\end{array}$ & $\begin{array}{c}\text { Falta de } \\
\text { profissional }\end{array}$ & $\begin{array}{c}\text { Altos } \\
\text { investimenos }\end{array}$ \\
\hline
\end{tabular}

Fonte: hotel A e B. Ano: 2011. 
Rev. Elet. em Gestão, Educação e Tecnologia Ambiental (e-ISSN: 2236-1170)

Antes de comentar sobre a Política Ambiental de cada hotel em estudo, torna-se necessário observar o comentário de Valle (2002) a respeito do tema. Segundo o autor, com base na Política Ambiental, deverão ser elaboradas diretrizes e normas internas, de conhecimento de todos os seus empregados diretos. Nesse sentido, a partir da análise desse estudo, percebe-se que o hotel A se encontra dentro do que foi traçado por Valle (2002). Dessa forma, após analisado o questionário respondido por ambos os empreendimento verificou-se que o hotel A possui: Política Ambiental bem divulgada internamente.

Esse fato torna-se mais perceptível quando comparamos a Tabela $1 \mathrm{com}$ as tabelas 3, 4 e 5 e ainda com a tabela 6 . As questões apresentadas na tabela 1 foram respondidas pelo gerente geral do hotel e a as questões apresentadas nas Tabelas, 3, 4 e 5 foram aplicadas a um funcionário de serviços gerais enquanto que as questões na tabela 6 foram respondidas por um funcionário da recepção. Realizando essa comparação, nota-se que não existem pontos divergentes quanto à divulgação da Política Ambiental no ambiente interno da empresa, uma vez que todos os funcionários possuem conhecimento das PGA que o empreendimento realiza;

Quanto ao cumprimento da legislação ambiental não foi possível averiguar a documentação junto ao órgão competente que negou o acesso à consulta pública. Contudo, uma vez que não foi possível verificar na SUDEMA se o hotel cumpre a legislação ambiental, tomou-se como referencia as informações repassadas pelo funcionário do setor de sustentabilidade que afirmou que o hotel está em cumprindo com a legislação ambiental vigente.

Já para o hotel $B$, apesar de o gerente geral do empreendimento responder que o mesmo possui uma política ambiental interna e que realiza práticas de gestão ambiental, foi possível perceber alguns pontos divergentes no questionário aplicado quanto a essa questão. Quando comparadas as tabelas 1, 3, 4, 5 e 6 é perceptível que a política ambiental da empresa não está bem divulgada internamente, uma vez que o gerente geral do hotel afirma realizar práticas ambientais e ações voltadas pra educação ambiental e ao mesmo tempo o funcionário de serviços gerais e o da recepção afirmam que não.

\subsection{ARQUITETURA E PRINCIPAIS IMPACTOS SOCIOAMBIENTAIS}

Quanto ao questionário referente à Arquitetura e Principais Impactos socioambientais (Tabela 02), este respondido pelo funcionário do setor de sustentabilidade, verifica-se que o hotel A atingiu um de total de 7 pontos, sendo classificado como o hotel que possui uma arquitetura que aproveita as condições alternativas para construção. Destaca-se que o Hotel B alcançou 9 pontos e que não foi possível verificar in locu o aproveitamento das condições naturais para construção do empreendimento 
Rev. Elet. em Gestão, Educação e Tecnologia Ambiental (e-ISSN: 2236-1170)

Tabela 2: Arquitetura e Principais Impactos Socioambientais

\begin{tabular}{|l|c|c|}
\hline Perguntas & Hotel A & Hotel B \\
\hline $\begin{array}{l}\text { Na construção do hotel foram levados em consideração a minimização } \\
\text { dos impactos ambientais provenientes das instalações físicas do } \\
\text { empreendimento? }\end{array}$ & Sim Sim \\
\hline $\begin{array}{l}\text { O material utilizado na construção do empreendimento é proveniente } \\
\text { de empresas que fazem a reutilização de resíduos? }\end{array}$ & Sim & Não \\
\hline $\begin{array}{l}\text { O hotel usa os elementos naturais para aumentar a ventilação e } \\
\text { iluminação natural da instalação visando evitar o consumo } \\
\text { desnecessário de energia? }\end{array}$ & Sim & Sim \\
\hline $\begin{array}{l}\text { Para a decoração interna do hotel foram utilizados móveis } \\
\text { ecoprojetados ou que façam uso das práticas do ecodesing? }\end{array}$ & Sim & Sim \\
\hline $\begin{array}{l}\text { O hotel procurou planejar a construção do empreendimento visando } \\
\text { crescimento futuro da instalação, de forma a minimizar demolição e } \\
\text { gastos futuros? }\end{array}$ & Sim & Não \\
\hline
\end{tabular}

Fonte: hotel A e B. Ano: 2011.

Para início da análise do fator Arquitetura e Principais Impactos Socioambientais verifica-se os principais impactos ambientais registrados por cada hotel. Quando indagado a respeito dos impactos ambientais gerados pelo empreendimento, o funcionário do setor de sustentabilidade do hotel A respondeu: "Os principais impactos ambientais estão relacionados ao são consumo de água, energia, material de limpeza e geração de resíduos diversos" (outubro, 2011).

Já o funcionário do hotel B respondeu: "Favoreceu a redução da ventilação junto com as demais construções na orla da capital" (outubro, 2011).

O relato acima mostra que o hotel A possui uma visão diferenciada quanto ao uso dos recursos naturais e aos impactos socioambientais gerados pelo desenvolvimento das atividades do empreendimento, quando comparado ao hotel B. Para o hotel B o principal impacto registrado seria o fato da redução da ventilação, contribuindo, no entendimento do empreendimento, uma ilha de calor no interior município de João Pessoa, PB, uma vez que o hotel se localiza na orla e por isso impede a entrada da ventilação natural para o interior do município. Entretanto, se o funcionário do setor de sustentabilidade diz que o hotel levou em consideração a minimização dos impactos ambientais provenientes das instalações físicas do empreendimento, esse tipo de impacto ambiental não deveria ter ocorrido. Segundo informações disponíveis no site do hotel B, o empreendimento faz uso da climatização artificial, e por isso, não faz proveito da ventilação natural. Porém, quanto à iluminação natural, o empreendimento realmente parece fazer proveito, já que as extremidades do hotel são de vidro, o que facilita a penetração da luz solar ao mesmo tempo em que gera outros impactos.

\subsection{PRÁTICAS DE GESTÃO AMBIENTAL - GERENCIAMENTO DOS RESÍDUOS SÓLIDOS}

Em relação às Práticas de Gestão Ambiental referentes ao gerenciamento dos resíduos sólidos (Tabela 03) o hotel A alcançou 11 pontos no total, e por isso foi classificado como o hotel que melhor gerencia os resíduos sólidos. 
Rev. Elet. em Gestão, Educação e Tecnologia Ambiental (e-ISSN: 2236-1170)

Tabela 3: Práticas de Gestão Ambiental - Resíduos sólidos

\begin{tabular}{|l|c|c|}
\hline Perguntas & Hotel A & Hotel B \\
\hline $\begin{array}{l}\text { Existe uma política de tratamento dos resíduos sólidos produzidos } \\
\text { pelo empreendimento? }\end{array}$ & Sim & Não \\
\hline Existe coleta seletiva no hotel? & Sim & Não \\
\hline O hotel quantifica e classifica os tipos de lixo produzidos? & Sim & Não \\
\hline O hotel possui parceria com alguma cooperativa de catadores? & Sim & Sim \\
\hline $\begin{array}{l}\text { O hotel dispõe de tecnologias apropriadas para o tratamento de } \\
\text { resíduos orgânicos? }\end{array}$ & Não & Não \\
\hline $\begin{array}{l}\text { O hotel vende seus resíduos sólidos para empresas que fazem uso } \\
\text { desse tipo de material para outros fins? }\end{array}$ & Não & Não \\
\hline
\end{tabular}

Fonte: hotel A e B. Ano: 2011.

Pode-se verificar na Tabela 3 que o hotel A traçou uma política de tratamento dos resíduos sólidos; realiza coleta seletiva; possui uma parceria com cooperativa (Posto de Reciclagem Cabo Branco - vinculada à EMLUR, Empresa Municipal de Limpeza Urbana). Entretanto, quanto ao gerenciamento dos resíduos sólidos de origem orgânica, o hotel ficou a desejar.

Quanto as Práticas de Gestão Ambiental adotadas para o gerenciamento dos resíduos sólidos, o hotel $B$ atingiu 16 pontos no total, ficando atrás na classificação. A respeito do gerenciamento dos resíduos sólidos, a empresa não realiza Prática de Gestão Ambiental.

\subsection{PRÁTICAS DE GESTÃO AMBIENTAL - USO DA ÁGUA}

Quanto as Práticas de Gestão Ambiental voltadas pra o uso da água (Tabela 4), o hotel A fez uma pontuação total de 8 pontos, sobressaindo-se mais uma vez em relação ao hotel $B$.

O hotel A possui as seguintes Práticas de Gestão Ambiental com relação ao uso da água: faz reuso da água; possui estação de tratamento própria; realiza as Práticas de Gestão Ambiental citadas por Santos et. al. (2005) referentes uso de aparelhos econômicos em relação ao uso da água como descargas ecológicas, uso de sensores nas torneiras, dentre outras.

$\mathrm{O}$ hotel $\mathrm{B}$ atingiu 13 pontos no quesito uso da água. O empreendimento não trata a água utilizada, sendo essa realizada pelo Governo do estado da Paraíba, e só apresenta uma única PGA das elencadas por Santos et. al. (2005), que é a utilização de chuveiros com redutores de consumo de água. O hotel não faz uso de sanitários com baixo consumo de água, nem de equipamentos mais econômicos de uso da água, como também, não utiliza água da chuva para irrigar jardins. 
Tabela 4: Práticas de Gestão Ambiental - Uso da água

\begin{tabular}{|l|c|c|}
\hline Perguntas & Hotel A & Hotel B \\
\hline Hotel faz reuso da água? & Sim & Não \\
\hline Como o hotel faz para tratar a água utilizada? & $\begin{array}{c}\text { Possui } \\
\text { estação de } \\
\text { tratamento }\end{array}$ & $\begin{array}{c}\text { CAGEPA } \\
\text { realiza esse } \\
\text { tratamento }\end{array}$ \\
\hline O hotel faz uso de torneiras com sensor de presença? & Não & Não \\
\hline $\begin{array}{l}\text { O hotel faz uso de sanitários com baixo consumo de água nas } \\
\text { descargas? }\end{array}$ & Sim & Não \\
\hline O hotel utiliza chuveiros com redutores de fluxo de água? & Sim & Sim \\
\hline O hotel faz uso da água da chuva para irrigação de jardins e outros & Sim & Não \\
\hline $\begin{array}{l}\text { O hotel faz uso de equipamentos mais econômicos de uso de água } \\
\text { como, por exemplo, lavadoras de louças? }\end{array}$ & Sim & Não \\
\hline
\end{tabular}

Fonte: hotel A e B. Ano: 2011.

Na tabela 1 quando o Hotel B foi questionado sobre qual o principal obstáculo que a empresa enfrenta para adotar PGA, o hotel citou altos investimentos. Quanto ao quesito PGA para uso da água, percebe-se que esse não é um obstáculo tão grande, já que essas medidas de consumo de água estão bem disseminadas em diversos setores, não necessitando assim de altos investimentos.

\subsection{PRÁTICAS DE GESTÃO AMBIENTAL - CONSUMO DE ENERGIA}

A respeito das Práticas de Gestão Ambiental voltadas para o consumo de energia (Tabela 5), o hotel $A$ atingiu 11 pontos, enquanto que, o hotel $B$ marcou 13 pontos.

Tabela 5: Práticas de Gestão Ambiental - Consumo de energia

\begin{tabular}{|l|c|c|}
\hline Perguntas & Hotel A & Hotel B \\
\hline O hotel procura racionalizar o consumo de energia elétrica? & Sim & Sim \\
\hline O hotel faz uso de lâmpadas com baixo nível de consumo? & Sim & Sim \\
\hline O hotel utiliza lâmpadas com sensores de presença? & Sim & Não \\
\hline O hotel faz uso de energia luminosa gerada por fontes renováveis? & Não \\
\hline O hotel utiliza geradores de energia elétrica movidos por? & $\begin{array}{c}\text { Combustível } \\
\text { Fóssil }\end{array}$ & $\begin{array}{c}\text { Combustível } \\
\text { Fóssil }\end{array}$ \\
\hline $\begin{array}{l}\text { O hotel utiliza sensores que desligue automaticamente os elétricos } \\
\text { domésticos presentes nas unidades habitacionais após a saída do } \\
\text { hospede? }\end{array}$ & Sim & Sim \\
\hline
\end{tabular}

Fonte: hotel A e B. Ano: 2011. 
Rev. Elet. em Gestão, Educação e Tecnologia Ambiental (e-ISSN: 2236-1170)

O hotel $\mathrm{B}$ também respondeu que procura racionalizar o consumo de energia elétrica, no entanto, não faz uso de alguns PGA como: lâmpadas com sensores de presença, energia luminosa gerada por fontes renováveis, a climatização do hotel não possui sensores de presença, etc. Porém, como já comentado anteriormente, a situação do hotel A, embora tenha se classificado em primeiro lugar entre os dois hotéis investigados, não é muito diferente do hotel $B$.

Quanto ao quesito consumo de energia, é perceptível que ambos os hotéis possuem aspectos bem parecidos. Talvez seja pelo fato do consumo de energia elétrica ser mais oneroso economicamente para os empreendimentos.

\subsection{QUESTÕES RELATIVAS AOS CLIENTES}

Em relação às questões relativa ao perfis dos clientes, ambos os hotéis responderam que o perfil do seu cliente seria o visitante a negócio. Com permanecia, segundo o hotel B, de apenas 4 dias. O hotel A não citou o período de permanência do seu cliente.

Quando questionados se as Práticas de Gestão Ambiental desenvolvidas pelos hotéis surtiram algum efeito em relação ao seu cliente, o hotel A respondeu que sim. Segundo o empreendimento, os seus clientes abraçam a causa e escolhem se hospedar justamente pelo conceito de sustentabilidade adotado pelo hotel. E por isso houve um aumento na credibilidade do hotel perante a clientela. Já o Hotel B não verificou melhoria alguma, uma vez que este, segundo o funcionário da recepção, não realiza práticas de gestão ambiental.

\section{CONSIDERAÇÕES FINAIS}

De acordo com os resultados obtidos fica claro que o hotel A é o que possui o perfil socioambiental mais sustentável entre os dois casos estudados, uma vez que este alcançou uma pontuação total de 50 pontos. Pode-se afirmar também que esse empreendimento possui uma atitude proativa no que diz respeito ao uso e conservação dos recursos naturais e a busca pela sustentabilidade em suas atividades.

O hotel B marcou 71 pontos. O empreendimento possui alguns pontos divergentes perceptíveis quanto a sua política ambiental interna e isso acaba sendo muito preocupante para a coordenação das atividades. Dessa forma, verifica-se que o hotel B possui uma atividade reativa no que diz respeito ao uso e conservação dos recursos naturais e a busca pela sustentabilidade em suas atividades.

Dentre os impactos socioambientais registrados pelos hotéis em estudo, percebe-se que tais impactos estão mais relacionados ao consumo demasiado de alguns recursos naturais, tais como: água, energia elétrica e geração de diversos resíduos, como os sólidos e efluentes líquidos, não fugindo daquilo que a literatura científica cita comumente.

Quanto aos principais fatores que podem influenciar as empresas a adotarem um Sistema de Gestão Ambiental, verificou-se que ambos os hotéis citam o fator cumprimento da legislação ambiental. Entretanto, o hotel A também menciona a sensibilização da empresa como mais um fator de influência.

A partir da realização do levantamento das práticas de gestão ambiental desenvolvidas pelos hotéis, nota-se que o SGA (Sistema de Gestão Ambiental) se torna uma ferramenta imprescindível em âmbito organizacional, uma vez que tal sistema passou a ser a opção mais 
Rev. Elet. em Gestão, Educação e Tecnologia Ambiental (e-ISSN: 2236-1170)

utilizada pelo mercado mundial com intuito de diminuir os possíveis impactos socioambientais gerados pelas atividades empresarias. No entanto, seria oportuno verificar se o SGA é realmente uma ferramenta eficaz no gerenciamento do uso fruto dos recursos naturais por parte das empresas, procurando realmente minimizar o uso intensivo dos recursos naturais, ou se verdadeiramente pode ser classificado como uma ferramenta de mercado com o intuito de diminuir gastos, economicamente falando, para empresas.

\section{REFERÊNCIA}

ADAM, Roberto Sabatella. Princípios do ecoedifício: interação entre ecologia, consciência e edifício. São Paulo: Aquariana, 2001.

BRAGA, B.; HESPANHOL, I.; LOTUFO, J. G. C.; MIERZWA, J. C.; THADEU. M. L. de B.; SPENCER, M.; PORTO, M.; NUCCI, N.; JULIANO, N.. EIGER, S. Introdução à Engenharia Ambiental - 2a. Ed. São Paulo: Pearson Prentice hall, 2005.

DIAS, R. Gestão ambiental: responsabilidade social e sustentabilidade/ Reinaldo Dias. - 1. Ed. - 5. reimpr. - São Paulo: Atlas, 2009.

FERREIRA, J.L. A variável ambiental como componente na classificação da qualidade dos serviços - hotelaria. Universidade Federal de Santa Catarina - UFSC. Florianópolis, SC. 1999.

LEFF, Enrique. Saber Ambiental: Sustentabilidade, racionalidade, complexidade, poder/ Enrique Leff; tradução de Lúcia Mathilde Endlich Orth. 8Ed. - Petrópolis, RJ: Vozes, 2011.

MAY, P. H., LUSTOSA, M. C., VINHA, V. da.. Economia do meio ambiente: teoria e prática/ Peter H. May, Maria Cecília Lustosa da Vinha, organizadores. - Rio de Janeiro: Elsevier 2003 - 6a reimpressão.

MORAES, A. G. de. Avaliação da gestão ambiental dos hotéis de selva de na Amazônia, Brasil. Pasos, Revista de Turismo y Patrimônio Cultural, outubre, ano/vol. 6, número 003. Universidad de La Laguna, Espanha, 2008.

OLIVEIRA FILHO, J. E. D. Gestão ambiental e sustentabilidade: um novo paradigma eco-econômico para as organizações modernas. 2004.

PERTSCHI, I. K. Gestão Ambiental na Hotelaria: Um estudo da Aplicação de Indicadores Ambientais. IV SeminTUR Seminário de Pesquisa em Turismo do MERCOSUL. Universidade de Caxias do Sul - Mestrado em Turismo. Brasil, 2006.

PHILIPPI, A. Jr., RUSCHMAN, D. V. de M., Gestão ambiental e sustentabilidade no turismo. - Barueri - SP: Manole, 2010. - (Coleção Ambiental, v.9).

SANTOS, C. B. dos., SOUZA, M. T. S. de., BARBOSA, R. J. Gestão ambiental em empreendimentos hoteleiros: análise de práticas e de resultados em um estudo de casos múltiplos. III SEGet - Simpósio de Excelência em Gestão e Tecnologia. 2005.

SEIFFERT, M. E. B. Gestão ambiental: instrumentos, esferas de ação e educação ambiental/ Mari Elizabete Bernardini Seiffert. - 1. ed. - 2. reimpre. - São Paulo: Atlas, 2009.

VALLE, C. E. do. Qualidade ambiental: ISO 14.000 - São Paulo: Editora Senac São Paulo, 2002. 